\title{
EVALUATION OF THE THERAPEUTIC EFFECT OF KANAMYCIN (KM) AND STREPTOMYCIN (SM) IN THE TREATMENT OF MURINE LEPROSY IN RATS
}

\author{
Toyoho EUROHASHI \\ (Chief; Tuberculosis Department, National Institute of Health, Tokyo) \\ Takeyo TAKAHASHI, Shinnosuke OSHIMA \& Motoko UEMURA \\ (National Sanatorium, Oshima-seisho-en, Kagawa Pref.-Chief: T. Nojima)
}

White rats infected with the KUMAMOTO-strain of M. leprae murium were divided into 3 groups; the first was treated with $5 \mathrm{mg}$ of $\mathrm{KM}$ daily, the second with the same dose of SM and the third was remained as the non-treated control. After the treatment of 3.5 to 4.5 months animals were autopsied and the nodules at the site of inoculation were removed, weighed and emulsified. The emulsions were diluted in decimal system. Two smears were prepared from every dilution degree of the emulsion quantitatively and were stained with victoriablue simultaneous staining and malachitegreen-fuchsin staining respectively for the counting of the number of bacilli in $0.1 \mathrm{ml}$, and then total number of bacilli per leproma was calculated. After that, $0.5 \mathrm{ml}$ of $1 / 500$ dilution of the emulsions of nodules were inoculated subcutaneously into normal healthy rats and the development of nodule at the site of inoculaton was observed.

In the treated groups the weight of nodules were markedly lighter and the total numbers of bacilli per nodules were also smaller than the control group. In the control group, majority of the bacilli stained to malachitegreen and was typical rod shaped form, whereas in the treated groups they could not be stained by malachitegreen and represented granular or beaded form. Such a difference was more evident in the KM group than in the SM group.

Leprosy nodules which were produced by inoculation of the emulsions of the nodules from treated animals appeared much later than those produced by the emulsion from control animal.

From these results it is clear that the administration of KM or SM is very effective in the treatment of murine leprosy in rats. Further,malachitegreen-fuchsin staining seems to be usable in the evaluation of the therapeutic effect of medicaments enabling to show qualitative differences of murine leprosy bacilli between the treated and the untreated animals. 


\section{鼠瀨菌感染ダイコクネズミに対する Kanamycin (KM) 及び Streptomycin (SM) の治療効果判定について}

室欈豊穂

国立矛防衛生研究所結核部展:

高橋竹代・大島新之助・稙朴詐子 回立療堎所大島青松園（園長 野島 泰治）

(1958 年 4 月 28 日 受稿)

緒言

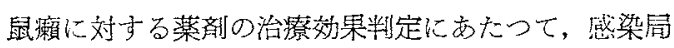
所鼠瀬結節の重量測定以外に, 結節内鼠瀨菌の定量的染 色鏡検を行つて，菌数の多少ならびに菌体の染色性觉比

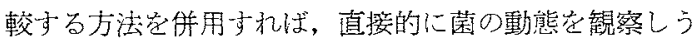
るので便利であるうとかつて報告した。いひ続き， Kananuycin (KM) 及び Streptomycin (SM) 总用いた

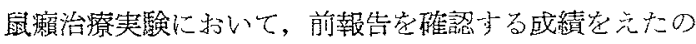
で報告する。

\section{実験材料並びに方法}

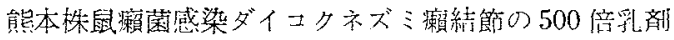
$0.5 \mathrm{ml}$ づっを下腹部皮下に接種されだ゙イコタネズミの

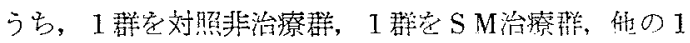
群を K M治療群七寸る。感染後75日日，綃節が-花分出現

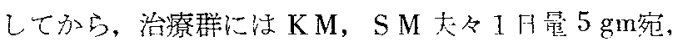
遗 6 回皮下注射した。治療継続 3.5 力月爱, 各群から 2

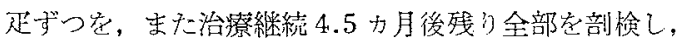

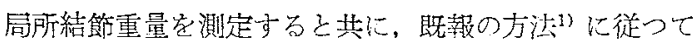
鼠獭結節中の菌数の推定を行つた。

守なわち，まず $100 \mathrm{mg} / \mathrm{ml}$ の結節乳都を $2 \mathrm{mg} / \mathrm{ml}$ trypsin 添加 phosphate buffer $(\mathrm{pH} 7.2, \mathrm{M} / 15)$ で作り, これ荐

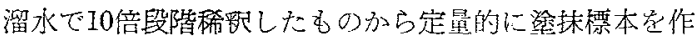
り, victoria blue 同時染色法2〉で染わた標本の訫数によ つて菌数を算定方ると共に, malachtegreen-fuchsin（M-

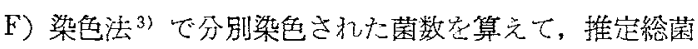
数および推定総緑染菌数を定めた。

また， 3.5 力月治療実験群については，対照およびK

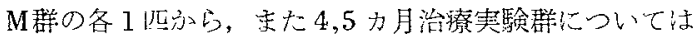

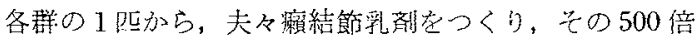

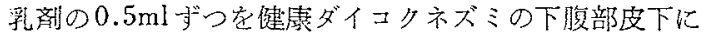
接種して，感染局所に生ずる瀨繥節炎観察し，各乳剂の 鼠攋発症力を比較した。

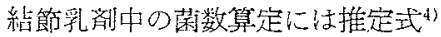

$$
\mathrm{N}=2 \cdot 10^{5} \cdot \mathrm{n}
$$

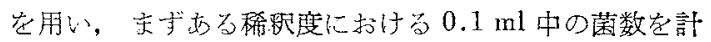
算して亦ら，こ礼に稀即度を乗して結節 $1 \mathrm{mg}$ 中の菌数 を,ついで全結節中の総菌数定覚出した。式中 $\mathrm{n}$ は 1 視 野平均萩数であ。

\section{実 験 成 績}

1. 結節重量ならびに結節中の菌数：

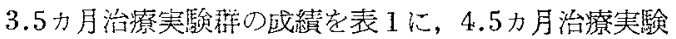
邦け成績を表 2 に揭げた，表中 $\mathrm{N}_{1}$ は $1 \mathrm{mg}$ 当り菌数， $\Sigma \mathrm{N}_{1}$ は全結節中菌数，宗た $\alpha$ は $\mathrm{M}-\mathrm{F}$ 染色で緑にそまる

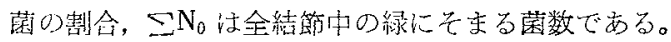

表 1. 3.5 力月治潦失駼群の鼠瀨結節重量と菌数

\begin{tabular}{|c|c|c|c|c|c|c|}
\hline 菇 & $\begin{array}{l}\text { Rat } \\
\text { Nos. }\end{array}$ & 重显( $\mathrm{mg}$ ) & $\begin{array}{c}\operatorname{lmg} w_{3} \text { 菌到 } \\
\mathrm{N}_{1} / \mathrm{mg}\end{array}$ & 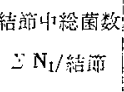 & $\begin{array}{c}\alpha \\
(\%)\end{array}$ & $\begin{array}{l}\text { 結節打緑菌数 } \\
\Sigma \mathrm{N}_{0} / \text { 結簛 }\end{array}$ \\
\hline 刘 & $1^{*}$ & 850 & $3.2 \times 10^{8}$ & $2.8 \times 15^{\mathrm{t1}}$ & 68 & $1.9 \times 10^{41}$ \\
\hline 照 & 2 & 880 & $3.6 \times 10^{7}$ & $3.2 \times 10^{10}$ & 93 & $2.9 \times 10^{10}$ \\
\hline \multirow{2}{*}{$\mathrm{S} \mathrm{M}$} & 3 & 400 & $2.8 \times 10^{7}$ & $1.2 \times 10^{10}$ & 22 & $2.6 \times 10^{9}$ \\
\hline & 4 & 340 & $1.2 \times 10^{7}$ & $4.1 \times 10^{9}$ & 67 & $2.7 \times 10^{9}$ \\
\hline \multirow{2}{*}{$\mathrm{KM}$} & 5 & 650 & $2.3 \times 10^{7}$ & $1.5 \times 10^{10}$ & 18 & $2.8 \times 10^{9}$ \\
\hline & $6^{*}$ & 150 & $1.0 \times 10^{7}$ & $1.5 \times 10^{9}$ & 13 & $1.9 \times 10^{8}$ \\
\hline
\end{tabular}

注： $\alpha$ ：M-F 染伦による緑染菌の蚛合

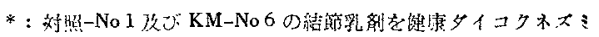
光下に接整(表3) 
表 2. 4.5 月治療実駼群の鼠瀨結節重琶と菌数

\begin{tabular}{|c|c|c|c|c|c|c|}
\hline \multirow{2}{*}{ 群 } & \multirow{2}{*}{$\begin{array}{l}\text { Rat } \\
\text { Nos. }\end{array}$} & \multirow{2}{*}{$\begin{array}{l}\text { 䝷 結節 } \\
\text { 重量 }(\mathrm{mg})\end{array}$} & \multicolumn{2}{|c|}{ ! Img当り菌数結節印総稛数 } & \multirow{2}{*}{$\begin{array}{c}\alpha \\
(\theta)\end{array}$} & \multirow{2}{*}{ 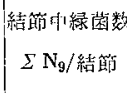 } \\
\hline & & & $\mathrm{N}_{1} / \mathrm{mg}$ & $\Sigma \mathrm{N}_{1} /$ 結節 & & \\
\hline \multirow[b]{2}{*}{ 好 } & 1 & 1,610 & $2.4 \times 10^{8}$ & $3.9 \times 10^{11}$ & 86 & $3.4 \times 10^{11}$ \\
\hline & $2^{*}$ & 1,740 & $2.3 \times 10^{8}$ & $4.0 \times 10^{11}$ & 83 & $3.3 \times 10^{11}$ \\
\hline \multirow{2}{*}{ 照 } & 3 & 980 & $5.3 \times 10^{7}$ & $5.2 \times 10^{10}$ & 60 & $3.1 \times 10^{10}$ \\
\hline & 4 & 840 & $3.2 \times 10^{7}$ & $2.7 \times 10^{10}$ & 49 & $1.3 \times 10^{\mathrm{t}}$ \\
\hline \multirow{6}{*}{$\mathrm{SM}$} & 6 & 130 & $6.0 \times 10^{5}$ & $7.8 \times 10^{7}$ & 12 & $1.3 \times 10^{7}$ \\
\hline & 7 & 130 & $7.0 \times 10^{6}$ & $9.1 \times 10^{9}$ & 18 & $1.6 \times 10^{9}$ \\
\hline & 8 & 220 & $3.3 \times 10^{7}$ & $7.3 \times 10^{9}$ & 32 & $2.9 \times 10^{9}$ \\
\hline & 9 & 250 & $2.8 \times 10^{7}$ & $7.0 \times 10_{9}$ & 58 & $4.1 \times 10^{9}$ \\
\hline & 10 & 250 & $2.2 \times 10^{7}$ & $5.5 \times 10^{9}$ & 45 & $2.5 \times 10^{9}$ \\
\hline & $11^{*}$ & 280 & $3.2 \times 10^{7}$ & $9.0 \times 10^{9}$ & 39 & $3.5 \times 10^{9}$ \\
\hline \multirow{7}{*}{ KM } & 12 & 60 & $3.4 \times 10^{6}$ & $2.1 \times 10^{8}$ & 9 & $2.1 \times 10^{7}$ \\
\hline & $13^{*}$ & 450 & $1.4 \times 10^{6}$ & $6.3 \times 10^{8}$ & 30 & $1.9 \times 10^{9}$ \\
\hline & 14 & 310 & $4.3 \times 10^{7}$ & $1.4 \times 10^{10}$ & 9 & $1.3 \times 10^{9}$ \\
\hline & 15 & 170 & $6.5 \times 10^{7}$ & $1.1 \times 10^{9}$ & 10 & $1.1 \times 10^{8}$ \\
\hline & 16 & 270 & $1.2 \times 10^{7}$ & $3.3 \times 10^{9}$ & 49 & $1.6 \times 10^{9}$ \\
\hline & 17 & 210 & $7.6 \times 10^{6}$ & $1.6 \times 10^{9}$ & 28 & $4.5 \times 10^{8}$ \\
\hline & 18 & 300 & $9.7 \times 10^{6}$ & $2.9 \times 10^{3}$ & 27 & $7.8 \times 10^{8}$ \\
\hline
\end{tabular}

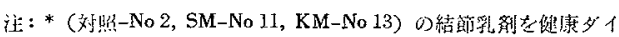
コタネメ゙ミ皮下に接程（表4）

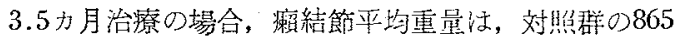
$\mathrm{mg}$ に対してKM群 $400 \mathrm{mg}, \mathrm{S} \mathrm{M}$ 都 $380 \mathrm{mg}$ で, 治療群で は結節重量が明ら加に少い。全結節中総菌数は，対照群 では $10^{10}$ 〜 $10^{11}$ order であるが，治潦群ではこ机より少 く, K M, S M禹群共 $10^{9} \sim 10^{10}$ order である。M-F法 による分別染色で緑にそ好分けられた菌の割合 $(\alpha)$ 注， 対照群の68\%及び93\%に対して，SM章 $22 \%$ 及び67\%，

K M群 $13 \%$ 及び18\%で，治療群で注に緑にまる菌数法明 らかに少く，とくにKM群で注著しい。全結節中の推定 緑染菌総数洼, 対照羣の $10^{10} \sim 10^{11}$ order に対して，治 療群では $10^{8} \sim 10^{9}$ orderで, 対照群のほぼ $1 / 100$ 程度に椙 当する。

菌の染色性ならびに形態をるると，刘照群では定型的 楻状を呈するものが大部分で, victoriablue, M-F 画染 色法により，乙もに良好な染色を示少が，KM群では是 型的桿状觉呈する緑染菌は少く，80９0\%先占好赤染 菌の多くは，捻珠状或は断裂した顆粒状定呈し，染色性 も悪い。SM群ではほぼその中間で，菌形態の正常のも のが相当見られ，吅染色性もKM群におけるよりも幾 分良好であった。

4.5 力月治療の場合の類結節平均重量は，対照群と治
療群とで注 3.5 力月治療の場合より一層差異が影著で, 対照群の 1,292 mg に站し, KM群 $253 \mathrm{mg}, \mathrm{SM}$ 群 $210 \mathrm{mg}$ である。すなるちち対照群では瀨結節の腫大が極めて著明 であるのに対して，治療群では何れも明らが濵結節が 縮小している。

全結節あたりの総菌数は, 対照群 $10^{10} \sim 10^{11}, \mathrm{KM}$ 群 $10^{8} \sim 10^{10}$ 及び SM 群 $10^{7} \sim 10^{9}$ order にあり，字た推定線 染菌総数は夫々 $10^{10} \sim 10^{11}, 10^{7} \sim 10^{9}, 10^{7} \sim 10^{9}$ order, で，3.5力月治療の場合よりも，一層緑にそまる菌数が 減少している。治療群，非治療群䦬の菌形態及び染色性 の違いは， 3.5 力月治療の場合よりも一罟顯著で, 対照 群では定型的桿状でしかる M-F 染色で緑にそまる菌が 王倒的に多いのに対して，KM 群では 3.5 力月沿潦の 場合よりも一層菌の染色性惊不良となり，M-F染色で fuchsinにより赤くをまる菌肪多く，加つ捻珠状及至顆 粒状を呈するものが極放て多い。SM群では，菌所見は ほじKM群に近いが、これに比して定型的䅞状を呈省る ものがキ゚や多かつた。

\section{2. 鼠顊結節乳剂の発症力}

3.5 力月治療実験㮍の対照 No I 及び KM-No 6 の癩結 節から夫タ 500 倍乳剂奆つくり，その $0.5 \mathrm{ml}$ ずつを健 尿ダイコクネズミ皮下に接種し，粘節形成経過を比較し

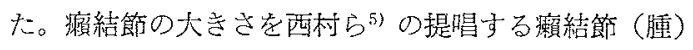
指数で表わせば裁 3 の如くで，対照 No 1 の結節乳剂に 比して，KM-No6のそれは著しく鼠瘷発症力の劣るこ

表 3. 3.5 力月治療実験群の結節乳郕 (500倍, $0.5 \mathrm{ml}$ ) 皮下注射後の鼠瀨結節形成経過

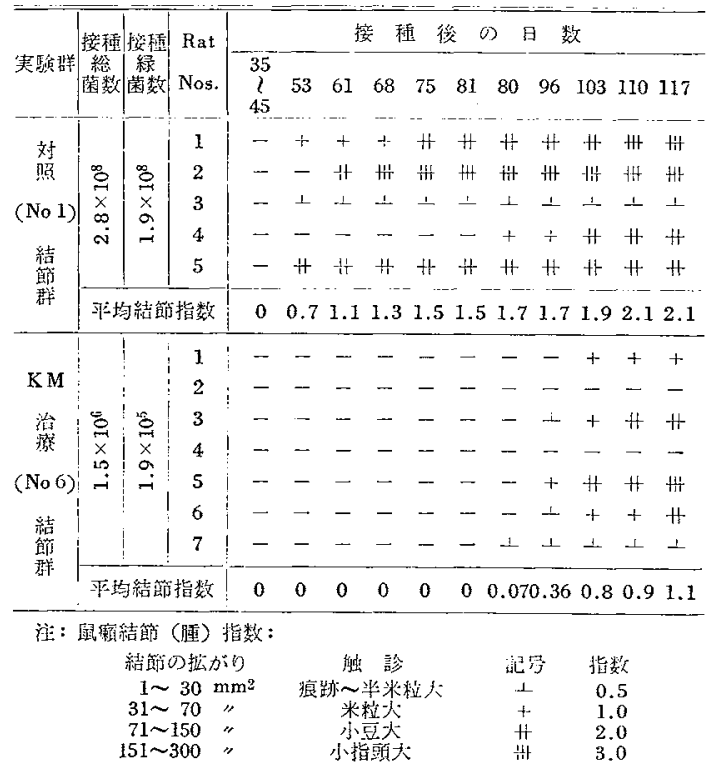


とが名が。

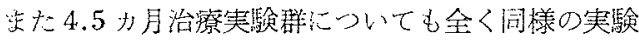
を行つだ。成績は表4の姐くで，KM-No 13 の乳剂によ

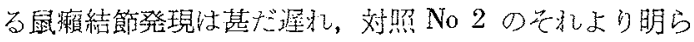

かに劣つている。また SM-No11の乳斉では半数に㧍い て獺結節は軽微であつたが，1匹では早期から明らかな

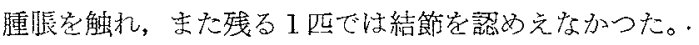
すなわ占 S M群の乳戍による発症状態には甚だ個体差が

裴 4. 4.5 力月治潦実験群の結節乳剂 $(500$ 倍 $0.5 \mathrm{ml})$ 皮下注射後の鼠癩結節形成経過

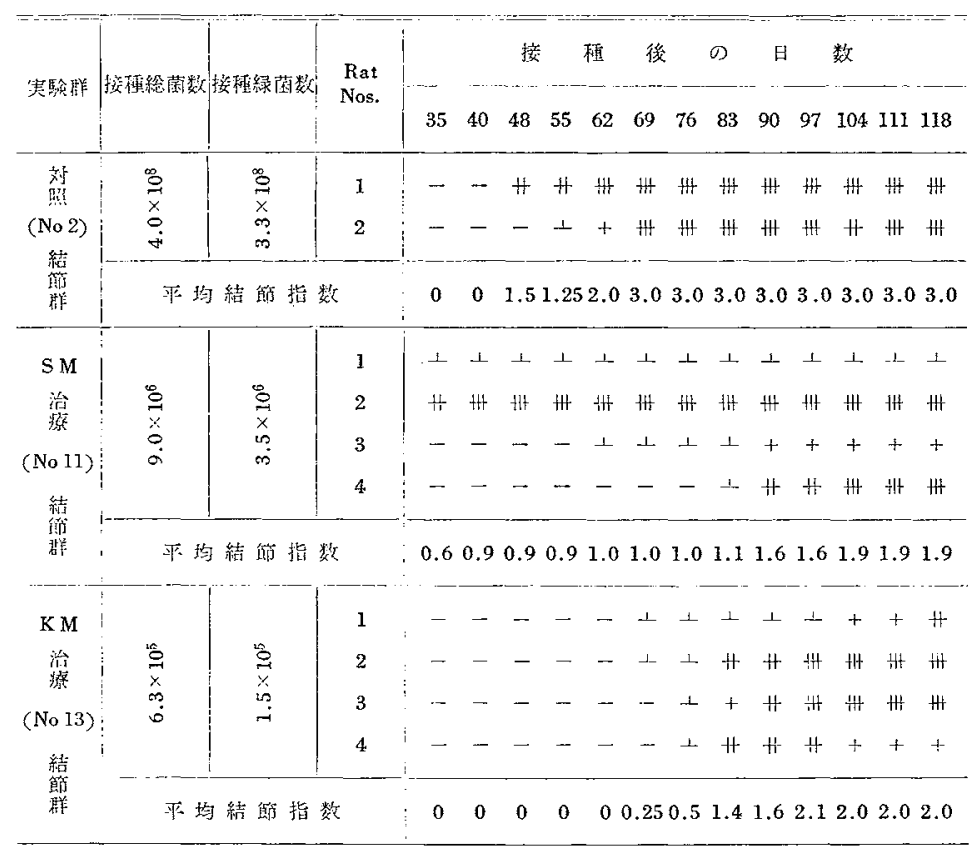

大きく，総体的に无机ば $\mathrm{KM}$ 群乳郕よりも登症力分户や 強いと考光ら机る。

\section{総 括・考 按}

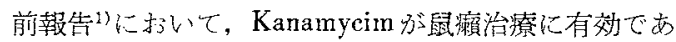
ること案述べた際に，治療效果判定には，徤来慣用され

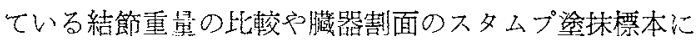
ついての菌検索に加元て，結節内鼠獺菌数の定量的測定 を行うべきこと提唱し， malachitegreen-fuchsin 法に よる菌体の分別染色の併用は，菌の質的な面の考察觉。 可能ならしめるので，しの目的に役立ちらるであるらと 速ベた。

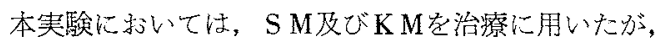
結節重量、結節内菌数ならびに菌の malachitegreen-fuchsin 法による分別染色性等の諸点に执いて，前報告に述 ベたところをとの字ま確認しうる成績字得た。この成績

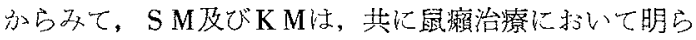
かに有效であるといらことが出来る。

本実験に新いては，さらに，分別染色された菌体の生

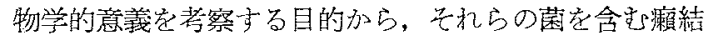
節乳刋痤唐ダイコタネズミ皮下に接種して発症力の比 較灻行つた。結果からみ扎は，接種乳郕中の総菌数にお いて，対照群乳剂と治寮群乳㓮との缃に既に2order以上

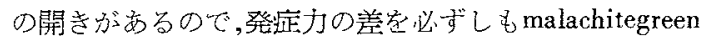

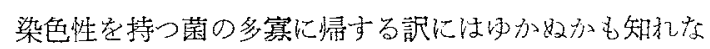
い。しかしその反面, 接種総菌数が癞結節発生に関与し うる生菌数をとのまま代表しえないこともまた考慮に入 れる必要加あるう。

ここで，結核節について得た観察炎想い起してみよ う。すなわ方, 結核菌の場合に, viable な菌は malachit.

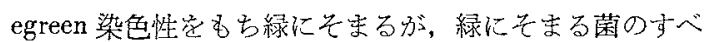
てが必ずしも viableではなく，李た緑にそまる菌の数が 著しく隇少与るらな環境条件下，例关沙濃厚菌液 $37^{\circ} \mathrm{C}$ 保存 ${ }^{3)}$ や濃縮空洞6)のような場合には，たとえある割合 に菌が緑に染まるうとも，培地上に拀いて分裂增殂しう る菌は少く，従つて集落形成もまた少いという成績をえ ている。鼠攋菌と結核菌とは勿論同じで恬なが，生物 学的諸性状の類佡性少らみて, 結核菌で得た知見は光 


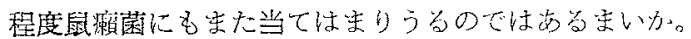

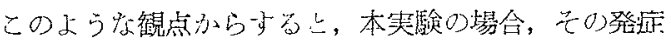

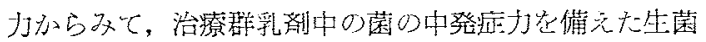
の数忹，前述の方法で計算さ扎た推定数小り実際的に は造加に少いのではない方と推察さ礼る。民して緑にそ まる菌方必ずしも马べて viableな菌ではないという結核 菌における知見に基ずけば，治療群乳風の1接種量中の viableな菌数は，対照群乳風のそれに比して1/1000よりさ らに低い orderにあつたのではないかと思わ虬るこの 点に関しては，接種菌数 order と鼠瀨結節形成程度とに ついて行われた西村らの実験成績) 加参考になる。その

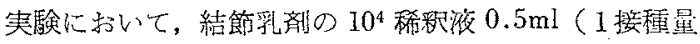
中の総菌数は $10^{6} \sim 10^{7}$ orderであつたと推察される) 艺 健康ダイコクネズミに接種した場合の瓦瘦結節登現経過 は，結節指数から灭て本実験の対照群のてれより幾分弱

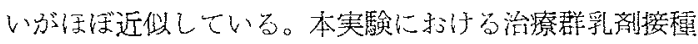
量中の総䒩数が $10^{5} \sim 10^{6}$ order であること考えると，

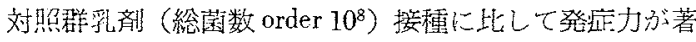
しく弱かつたことは，接種総䒩数の差以外に，菌の筫的

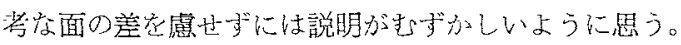

malachttegreen 染色性の菌数の多䔔亡発症力之定関連 ずけるたらには，勿論接種総菌数它同じ order 心規正し

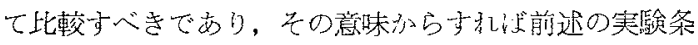
作はこの点炎検討与るに充分であるとはいいがたい。し か乙接種総菌数 orderの違いでは説明しがたい程の登庭 力の違いは，菌自体に，侏にその vitalityに抢りる著し

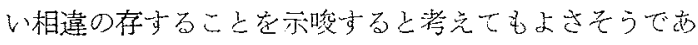

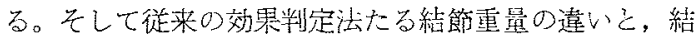
節内菌体の分別染色性ならびに菌形照の遠いがよく平行 するとこるからみると, malachitegreen-fuchsin染色によ

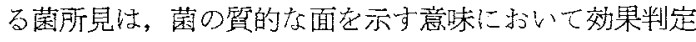
八の補助手段として用いらるように思わ机る。

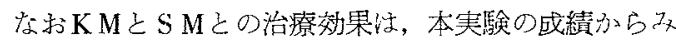
ると，同一投与覺ではKMの方が吊中優名といいうるだ あるう。

\section{結 論}

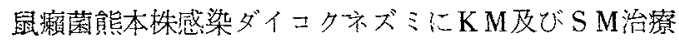
忌行い，3.5４.5\%月治噔継続後に屡殺して鼠癩結節重

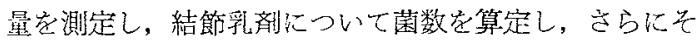

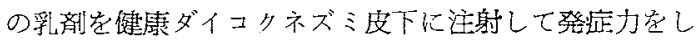
らベた。

治潦群では結節重量は対照群より軽く，全結節当り総 菌数を明らかに少なかつた。 malachitegreen-fuchsin染色
による揫前見では，治療群では malachitegreen 染色性を

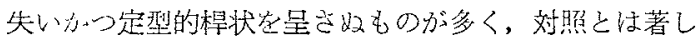
く異つていた。

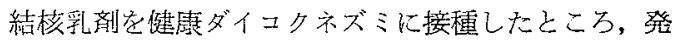
症力治療群ことにK M治療群乳戍が著しく劣つてい た。

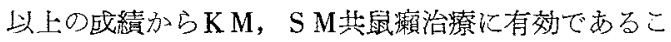
とがわかる。また malachitegraen-tuchsin 染色江は，治 療效果判定への補助手段として用いうると思う。

\section{文献}

1) 室橋豊穗: Kanamycin によるネズミ癩治療効果判 定への malachtegreen-fuchsin 染色汒の忍用・医学と生 物学, 48 ( 2), 49 (1958)

2）室憍豊稳・吉田幸之助: Hallberg 結核菌染色法の 一変法，Victoriablue によ台染色・日本医事新啹，1609 号, 987 (1955)

3) Murohashi, T. \& Yoshida, K.: Improvement of malachitegreen-fuchsin staining. Acta tuberc. scandinav., $36(2-3), 195(1958)$

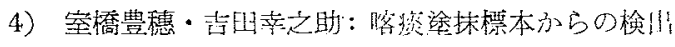
結核菌々数に基ついけ惟養集落数り推定法, I, II \& III. 絬核，33，95・293\&341 (1958)

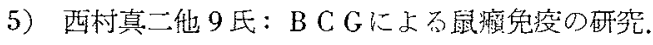
レプラ, 25(2), 25, 70 (1956)

6) 室橋豊穗・吉田幸之助・加納保之・洪野三吾：切

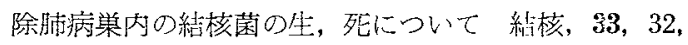
(1958) 